\title{
Ehlers-Danlos and respiratory function. Clinical data on a cohort of 5,700 patients: oxygen therapy and physical rehabilitation medicine (P.R.M.)
}

\author{
Claude Hamonet, 2,3* MD PhD, Régine Brissot MD PhD², Richard Amoretti MD³, Lucette Ducret $\mathrm{MD}^{4}$, \\ ${ }^{1}$ Occupational Therapy Department, University Paris-Est-Creteil, 80 Avenue du General de Gaulle, 94010 Creteil France. \\ ${ }^{2}$ ELLAsante, medical center, 29 bis rue d'Astorg, 75008 Paris. \\ ${ }^{3}$ Integrative Scientific Medicine 60 rue Carnot 92100 Boulogne-Billancourt France \\ ${ }^{4} 5$ route des 4 vents Le Lyonnet 74500 Saint-Paul-en-Chablais France.
}

*Corresponding Author: Claude Hamonet, 8 chaussee de l'etang 94160 Saint-Mande, France.

Received date: March 12, 2020; Accepted date: March 23, 2020; Published date: March $30,2020$.

Citation: Hamonet C., Brissot R., Amoretti R., Ducret L. (2020) Ehlers-Danlos and respiratory function. Clinical data on a cohort of 5,700 patients: oxygen therapy and physical rehabilitation medicine (P.R.M.). J Neuroscience and Neurological Surgery. 6(3); DOI:10.31579/2578-8868/122 Copyright: ( 92020 Claude Hamonet, This is an open-access article distributed under the terms of the Creative Commons Attribution License, which permits unrestricted use, distribution, and reproduction in any medium, provided the original author and source are credited.

\begin{abstract}
Ehlers-Danlos syndrome (EDS) appears today to be very common but is still, paradoxically, considered as rare because of a very scarce and belated diagnosis. Respiratory manifestations (exertional dyspnea, painful inspiratory bradypnea and sleep apnea are among the poorly understood manifestations of this diffuse inherited collagen disease. They can cause diagnostic errors, especially with asthma, which can lead to worsening, in these patients with very fragile tissues (including bones), contraindicating corticosteroid therapy. EDS should be systematically discussed in case of respiratory disorders in children but also in adults. There are very beneficial effects observed with oxygen therapy which considerably helps with symptoms such as fatigue, migraine, cognition, by correcting cerebral anoxia which accompanies it. Pneumologists should be made aware of the benefits of oxygen therapy when faced with an EDS patient as they may have to prescribe it.
\end{abstract}

Keywords: ehlers-danlos, breathing pauses, sleep apnea, pneumothorax, chest pain, dyspnea, asthma, 1-dopa, ribs lidocaine injections, orthoses, compressive garments, oxygen therapy.

\section{Introduction}

EDS appears to be very common today (1) but it is still, paradoxically, considered as rare because very scarcely (2) and often belatedly diagnosed (3). One reason is the incomplete description of its multiple symptoms. Among the clinical manifestations forgotten by the first descriptors $(4,5)$ are respiratory manifestations (exertional dyspnea, painful respiratory bradypnea, sleep apnea) which are frequent (6) and may lead to incorrect diagnoses and treatments that worsen these very fragile patients. More severe complications are possible: laryngeal edema, pneumothorax, atelectasis, swallowing disorders with false routes, and bronchial flooding by gastric reflux. It is therefore important to consider EDS instead of asthma, sleep apnea, heart pain or, above all, as is too often the case, psychosomatic disorders. This will enable to set up prevention and new suitable treatments for this disease, including discontinuous daily oxygen therapy, which has largely shown its effectiveness for several years, on all the manifestations of this complex disease, in particular on respiratory symptomatology (7).

Knowledge about this hereditary disease, transmitted to all the children of an affected person (8), has evolved considerably over the past twenty years. Diagnosis is now possible based on clinical data alone (6). It can be confirmed by electron microscopy (9). Patients suffer from doctors' ignorance. Their physicians do not diagnose their pathology (10) and do not offer appropriate treatments. They are impressed by the diversity and intensity of symptoms contrasting with the negativity of imagery and biology. Their practitioners do not believe these patients and are convinced that psychological factors, possibly associated with asthma, are responsible for the clinical picture which induces, often from childhood, negative attitudes on the part of family and school friends. Sometimes, there are false accusations of parents 'mistreatment with catastrophic withdrawal of affected children in presence of bruises, spontaneous fractures. One can even see suspicion of Munchausen syndrome by proxy (11) due to numerous medical consultations linked to symptoms multiplicity with normal imaging and biology.

\section{From symptomatology to pathophysiology of Ehlers- Danlos disease.}

Ehlers-Danlos is not a syndrome (12), as Achille Miget named it in his medical thesis in Paris in 1933 (13), as it is abusively called up to now, but a unique disease with multiple clinical expressions (14). It is a disease of the whole connective tissue, which explains plethora of observed clinical forms. Characteristics of connective tissue involvement in these patients can be summarized by the terms hyperlaxity and fragility. Hyperlaxity, associated with a decrease in tissues elasticity, is responsible for the misleading and variable characteristics of messages sent by sensory and sensorial sensors placed in connective tissues to a nervous system which is free from any lesion, and programmed to receive different signals. This results in a generalized proprioceptive disorder which 
explains all the motor, sensory and sensorial disorders observed. The other consequence is the very significant fragility of the entire connective tissue causing hemorrhages, eventrations, intestinal obstructions, skin or mucosal injuries, during surgical procedures or endoscopies.

Signs which allow diagnosis are the expression of these two characteristics. Diagnosis is possible by highlighting the presence of 5 of the 9 following signs with a sensitivity of $99.6 \%$ and a fidelity of $97.1 \%$ $(6,15)$ : diffuse and permanent pain reinforced during crises and rebellious to treatments, very significant fatigue, motor control disturbances, joint instability, fragile skin, joint hyperlaxity, hemorrhagic tendency (bruising, gingivorrhagia, menorrhagia), hyperacusis, gastric reflux. These signs join those proposed by Rodney Grahame (14) and Antonio Bulbena (17) by completing them. They are also present in the 2017 New York classification project (18). There is therefore a broad international consensus on the clinical identification of this disease, despite uncertainties concerning its biogenetic diagnosis (16). Discovery of similar cases in ascendants, descendants and collaterals provides the clinical genetic evidence that biogenetics is still struggling to confirm.

\section{Respiratory manifestations of Ehlers-Danlos disease.}

Careful observation of a cohort of 5,700 patients, followed over a period of more than 20 years, enabled us to group together a set of 79 signs, among which are the following respiratory manifestations, French pneumology company (19).

\section{Dyspnea}

It is a dyspnea on mild exertion which can be observed when climbing stairs ("sign of the staircase") or during brisk walking. It was present in $83 \%$ of the cases in a series of 823 of our patients (6). It is not "exercise asthma" but of one of the expressions of Ehlers-Danlos disease's global proprioceptive syndrome. Tendons' mechanoreceptors (Golgi's corpuscle), neuromuscular spindles and lower limbs joint ligaments' mechanoreceptors (20) which are connected to the respiratory centers do not send messages informing them of an effort implementation and therefore an increased need for oxygen. Use of special compression garments, K-taping for athletes (21), knee braces, increasing proprioceptive sensations as well as physical activity which has the same effects, are means of improving mechanoreceptors action on respiratory control. We have also observed that prescribed intermittent daily oxygen therapy clearly improves (7) this dyspnea on exertion. The explanation is perhaps the improvement in deficient oxygenation of the nervous system, including respiration regulation centers. Oxygen transport difficulties by a faulty vasomotor system subjected to dysautonomia worsens the situation $(22,23)$.

\section{Apneas.}

They are often observed and usually reported as asthma attacks. However, these are inspirational, not expiratory, bradypneas. The mechanism involved is diaphragmatic and all the respiratory muscles blockage by one or more pain starting at a costal point. Ribs, which are rich in connective tissue, are particularly flexible and their deformation causes very sharp pain at the inspiratory muscles' insertions which provokes respiratory blockages. Physical examination easily finds these painful areas, especially at the xyphoid level (we called this last localization the Ehlers' point because of its very high frequency and the very disabling role of the pains located at this level), and the lower rim twelfth right and left ribs. These trigger zones can be found on the whole thoracic cage, on its anterior face, often at the level of the sterno-costal or acromioclavicular joints and in the posterior thoracic region, especially in its lower part. Highlighting these trigger points, during soft palpation of these areas (the pains caused by the examination can be very intense and lasting) makes it possible to guide the needle which will inject local anesthetic and, most often, to immediately lift thoracic oppression providing the therapeutic proof of its origin. Discovery of painful costal areas eliminates a heart cause, often mentioned if the pain is precordial. However, possibility of heart pain during extrasystoles, due to dysautonomia, also responsible for palpitations, should be noted. These manifestations can also be part of a POTS (Postural Orthostatic Tachycardia Syndrome) with blood pressure drop, general feeling of weakness (floppy baby syndrome), fall and confusion. Breathing pauses, which can cause alarming brutal awakenings, can be observed during sleep or when falling asleep due to lower alertness of respiratory centers during these periods. They should not be confused with sleep apnea. These breathing control difficulties may explain periods of polypnea sometimes observed by pneumologists during functional respiratory tests.

\section{Bronchial manifestations}

Bronchi are part of the connective tissue and present alterations common to all these tissues. They can collapse, favoring a bronchial obstruction which can be complicated by atelectasis, or be very dilatable, with stasis and infections. Radiological aspects, wrongly evoking a bronchiectasis are possible. In all cases, the low contractile efficiency of the bronchial system does not promote hypersecretion's product evacuation, which is frequent, favored by susceptibility to infections, especially in childhood, and increased reactivity to allergens. These two aspects possibly stem from mast cell activation syndrome very often observed in these patients. Frailty of histamine-rich mast cells is favored by connective tissue, in which these cells are located, fragility. This justifies the preventive use of antihistamines. Bronchitis in infants and children was very common in our cohort (73\%). (6). Their repetition, their severity, their resistance to treatments, should attract attention and evoke this connective tissue's pathology. Cough reflex can be exaggerated in this pathology with hypersensoriality and can be responsible for coughing fits that are sometimes difficult to control. Disturbance of the aerodigestive crossroads' sensations and perhaps dystonia, are at the origin of false routes. They are frequent, annoying but, most often, well controlled. Sometimes, they are more massive, especially in bottle-fed infants or in case of gastric reflux, very common in this pathology (74\%). Mucous membranes' hypersecretion is not limited to bronchi alone, but also concerns mouth, nasal cavities, sinuses, pharynx. Aerosols using mucolytics and non-corticoid anti-inflammatory drugs can be used to relieve symptoms. Corticosteroids repeatedly must be avoided because of the risk of diffusion into the blood. Corticosteroid therapy, often used in our patients, is contraindicated because of the osteopenia worsening risk, usually present in this disease. There is one exception to this rule: the occurrence of laryngeal edema (7) with asphyxia syndrome which fully justifies parenteral corticosteroid therapy.

\section{Hemoptysis.}

Bronchial or stomach tissue frailty can be responsible for hemoptysis, reduced, most often, to a few streaks of blood in sputum. This phenomenon is commonplace in Ehlers-Danlos disease and blood can be 
found in urine, stool, and gum tissue. It is common to say that "in EhlersDanlos disease, the patient is bleeding everywhere." Bleeding can be caused more dramatically by endoscopy, which should be avoided for the only benefit of imaging. Risk is increased if a biopsy or excision of polyps, frequent in this pathology and with very low risk of degeneration, is performed.

\section{Dystonia.}

Is frequent but poorly understood and often confused with epilepsy or wrongly described as a hysteria attack. It can be responsible for breathing difficulties during generalized muscular discharges, combined with contractures affecting thoracic region. Its treatment combines oxygen therapy, effectiveness of which was measured directly during a generalized crisis that occurred during our consultation, and L-Dopa. The latter must be used in prevention in presence of evocative signs: involuntary shoulders or limbs' muscle twitching, extremities' contractures, face or limbs' muscular fasciculations, tremors, restless legs when falling asleep, bruxism at night.

\section{Tumors, cysts, lymph nodes.}

Peculiar structure of connective tissue in this disease is responsible, at time of apoptosis, for unusual tissue overgrowths in form of cysts, nodules, tumors, angiomas or lipomas, but also of meningiomas. Cysts, nodules and tumors can be observed everywhere in the body, including in the lungs and pleura. Most often, they disappear spontaneously, and we did not observe in our cohort cases of degeneration. Lymph node enlargements are also frequent, transient. They can be mediastinal.

\section{Pleural effusion.}

Tissue laxity promotes stasis in form of edema, intra-articular effusions but also pericardial or pleural effusions. Careful evacuation due to tissue fragility may be necessary.

\section{Pulmonary emphysema. Pneumothorax.}

They were very rare in our series (6 cases) but none of these cases were linked with EDS. They reacted well to usual treatments. Some recurred with a positive effect of therapeutic resumption. EDS and the tissue weaknesses that accompany it, should be better known as a possible cause of spontaneous pneumothorax.

\section{Rib cage lesions.}

Rib fractures and sterno-costal, sterno or acromio--clavicular, costovertebral and xyphoid dislocations can be seen. Pathologically increased costal cartilages' plasticity promotes their painful deformation but also fractures, most often without displacement, and dislocations. These manifestations are particularly frequent in children, born to a mother suffering from Ehlers-Danlos disease, therefore deficient in vitamin D. The child himself has very fragile bones in the first months of his life as long as his deficit in Vitamin D, which cannot spontaneously compensate for, has not been corrected by food intake or supplementation. Consequence is the possibility of spontaneous fractures when lifting the child, holding him closely, or even simply setting him in lateral decubitus. Focus on violence against children often results in accusation of parents' violence against their child. When the justice system decides withdraw custody serious consequences ensue solely based on a doctor or a social worker's who does not know EDS, as is commonly seen (24). A sign deserves a special mention: sharp pain at the xiphoid or immediately subxiphoid region's pressure. We gave it the name of "Ehlers' sign" because of its frequency and the important role that these pains with respiratory blockages hold in the course of the disease. The great flexibility of this small bone fixed at the lower end of the sternum, increased in EhlersDanlos disease, exposes it to very painful reactions associated with pain in the joints near the twelfth ribs. This is the epicenter of costal pain responsible for the diaphragmatic blockages responsible for inspiratory bradypnea often observed in Ehlers-Danlos disease. Xylocaine local applications, by injection (25), patches or gels, usually have spectacular and lasting effects.

\section{Functional respiratory investigations.}

Most often, apart from crises, they are within normal limits. A special case is the presence of significant scoliosis with vital capacity restriction, stabilized by Harrington stem or Cotrel-Dubousset's intervention. Blood oxygen is within normal limits, even after effort, in most of the cases. The nineteen 6 minutes tests, carried out with difficulties, because functional limitations in walking, do not reveal any anomalies. Limitation of physical activities is however very frequent and appears to be an important factor of clinical aggravation. Reduction of the sensitivosensorial messages sent to the brain aggravates the proprioceptive syndrome. This is corroborated by clinical observations: patients who have the least symptoms are the ones who have maintained an important physical activity (some, even, are competitive sportsmen) stressing their nervous system.

Exercise tests performed on more than 1.000 of our patients have shown a developed power 10 to $20 \%$ lower than that of a reference population. These tests should be done in moderation or avoided in the most painful patients. Very athletic patients are the exception with their results identical to those of the ordinary population. Often there is a slow and insufficient increase in exercise Blood Pressure. These stress tests make it possible to set up sports activity advice, an activity that must be daily, at least one hour per day, but essentially in endurance, staying below the onset of pain threshold.

\section{Ehlers-Danlos. From pathophysiology to treatments.}

Four therapies have emerged as effective and specific in influencing and, at times, transforming the clinical expression of Ehlers-Danlos disease, including respiratory manifestations. These include Lidocaine injections into the trigger zones, proprioceptive disorders treatment with special compression garments and orthotics, dystonia treatment with L-Dopa and daily intermittent oxygen therapy. Other treatments are symptomatic, especially against pain with an indirect effect on respiratory activity.

Local injections (25) of a few drops of local anesthetic (Lidocaine 20 to $40 \mathrm{mg}$ per $\mathrm{ml}$ ), in the area of rib pain in contact with insertions of the intercostal muscles, xyphoid, sternocostal or costo-vertebral joints, but also with a slightly larger volume, accessory inspiratory muscles (Pectoralis major, trapezius, sternocleidomastoid, serratus anterior, latissimus dorsi) have immediate and very often lasting effects, from a few weeks to several months and can be repeated several times in a week. In their absence, patients can apply Lidocaine patches or gels which easily pass through their very thin skin.

Compression garments specially made for Ehlers-Danlos disease (26) can be used combined with a lumbar belt, preferably with triple support 
(scapular in front and pelvic in back) helping to reinforce the trunk position sensations through the central nervous system. These trunk orthoses facilitate the breathing control thanks to their proprioceptive effect and their facilitating the diaphragm and abdominal muscles' movements, during expiration. Use of muscular assistance devices made for athletes (Taping) have identical effects and are to be widely recommended, combined with clothing and orthotics of the trunk effective at thoracic level and can help, combined with the previous treatments.

Low-dose L-Dopa (125 mg extended release in the morning and $62.5 \mathrm{mg}$ in the evening) is indicated in case of dystonia (sudden, involuntary movements, tremors, myoclonus, especially of the face). It decreases pain frequency as well as its intensity and generally improves automatic motor skills (27). In this way it plays a role in breathing difficulties which it can help to alleviate.

Oxygen therapy is prescribed in sessions of 20 minutes or more, as needed, two to four times a day, preferably through mask, using an oxygen extractor or liquid oxygen, with humidifier (frequent dryness of mucous membranes). It mainly relieves fatigue and migraines. A recent series of 113 patients were compared to themselves before and after a month or more of oxygen therapy. Results analysis was performed using a 5-level Licker scale (0: no effect, 1: discrete effect, 2: medium effect, 3: significant effect, 4: very significant effect). A score equal to or greater than 2 was observed in $81 \%$ of cases in fatigue and $76 \%$ in migraines.

Detailed analysis of oxygen therapy modalities of use in 40 of these patients highlights a very high level of attendance ( $75 \%$ of daily use 7 days a week) and in other cases an adapted to symptoms use. The sessions' duration goes beyond the 20 minutes recommended, it is 30 minutes or more. The flow of oxygen per minute is relatively high (4 to 5 liters in $57 \%$ of cases). Mentioned side effects are nasal mucosa irritation, intolerance to the nasal canula or masks and incommodation of these hyperacusic patients by the concentrator's motor noise.

A validation trial asking patients to stop their treatment for a week had to be abandoned because the patients could not tolerate stopping oxygen therapy and spontaneously resumed it. These figures are similar to those already published in 2016 (7).A retrospective study was carried out by direct interviews and questionnaires in 128 Ehlers-Danlos patients, among them some children using regular oxygen therapy at home and at school over a period of 1 to 37 months (average: 14 months). The cohort included 117 women and 11 men aged 5 to 81 years. For fatigue, improvement is considered important or very important by patients in $51 \%$ of the cases and slight or average in $37 \%$ of the cases. Finally, $79 \%$ of the cases have been improved. For migraines, amelioration is very important in $65 \%$ of cases and mild or moderate in $40 \%$ of cases. Another prospective study on 30 cases, one month after oxygen therapy introduction confirmed this result. It is beneficial to practice these sessions before physical activity including physiotherapy session. Repeated upper airways stimulation by Impulsator $\mathrm{HC}$ ( (Percussionnaire $\left.{ }^{\circledR}\right)$ in 20 minutes sessions, combined with oxygen therapy, have shown their effectiveness (7) on false routes prevention, dysphonia, and pharyngo-laryngeal spasms, by improving proprioception of this region. These manifestations also benefit from aerosols associating mucolytics and anti-inflammatories, avoiding corticosteroids because of the risk of diffusion, in all these hypersecretions and irritations of the respiratory tract. Corticosteroid therapy is contraindicated because of the risk of osteopenia worsening usually present in this disease. There is one exception to this rule: occurrence of laryngeal edema (7) with severe dyspnea which fully justifies it.

\section{Contribution of digestive and food hygiene}

Preventing gastroesophageal reflux by prescribing anti-reflux, head-up position during sleep, precautions when swallowing fluids, regular moistening of the mouth, good oral hygiene (teeth, in this disease, are fragile, often prone to cavities), wearing a palatal groove with proprioceptive aim improves chewing by avoiding temporomaxillary joints' pain and dislocation, food fractionation during meals, help protect bronchi and avoid painful, ineffective coughing fits. Improvement of ventilatory mechanics calls for fighting abdominal bloating (including a low gluten diet), constipation, massaging abdomen, and strengthening abdominal muscles.

\section{Vaccinations against influenza, and bronchial infections in small children, are indicated.}

Physical medicine contributes to improvement of respiratory proprioception by global exercises but Tai Chi Chuan and Qui Cong, singing (which is sometimes of excellent quality in these patients), playing a wind instrument are also recommended. Swimming, scuba diving, horseback riding also has this type of beneficial effect. Efficiency is linked to regular repetition of exercises. We offer a preventive selfeducation program to be carried out every day. The aim of these exercises is to strengthen proprioception, muscular, thoracic, bronchial to ensure an "awakening" of respiratory regulation centers. All exercises are to be performed with the orthotics prescribed for Ehlers-Danlos disease: trunk and lower limbs, including plantar orthotics to increase their proprioceptive effects. As far as possible they are performed in standing position, with support if necessary, in order to be more effective by having to fight against abdominal pressure. It is desirable to practice them after an oxygen therapy session to improve muscle contractions' quality and better tolerate verticality effects on the neurovegetative system (POTS). These are isometric contractions (without segmental displacement) so as not to cause pain, brief ( 7 seconds) so as not to create fatigue, alternating work and rest at equal time, equal duration of contraction ( 7 seconds) and rest to cause a change in sensation between activity and muscle rest, which is the same as slowly counting to 5 . The period of muscle relaxation is accompanied by an open mouth expiration while contracting the abdominal muscles. Each series of 7 seconds of contraction and 7 seconds of rest is repeated 5 times. The muscular contractions requested concerned cervico-thoracic muscles, dorsal muscles and pelvic floor muscles. Patient is asked to simultaneously "tuck his head in the shoulders", "squeeze the shoulder blades against each other by pulling his arms back", "contract anus, as if the patient wanted to prevent the 'emission of a gas'. For the forced expiration time, it is asked to "pull the stomach in". Simultaneous contractions of the concerned muscle groups create a set of stresses intended to strengthen the mechanoreceptors' perception.

\section{Prevention of iatrogenic accidents.}

Due to diagnosis misunderstanding, tissue fragility and specific proprioceptive reactions, some investigation techniques or treatments are contraindicated or incite to special precautions. Arterial punctures must be avoided because of arterial rupture risk which is very difficult to control. Due to the veins' frailty, venipunctures and infusions are difficult, hemorrhagic. Mucous membranes' fragility contraindicates, unless 
absolutely necessary, respiratory tract's endoscopies. Knowledge of Ehlers-Danlos disease - providing the answer to most symptoms that could motivate it. A fatal case of pharynx wound in a relative was brought to our attention by a patient. Osteopathic spine manipulations are formally contraindicated, because of neurological complications risk but above all a dramatic worsening of the patient's clinical picture as we have just published (28). Use of morphine drugs is prohibited: their action on pain is uncertain, addictions are very difficult to treat, side effects are important on the overall self-perception and on the intestine with occlusive accidents. Corticosteroids, apart from laryngeal edemas, already mentioned, are to be excluded because of brittle bones. Intensive bodybuilding physiotherapy is poorly supported and responsible for worsening pain. Antidepressants help worsen proprioceptive syndrome and should be avoided. Constant anxiety (17) can, however, benefit from very mild anxiolytic treatment combined with psychological support and relaxation techniques.

\section{Conclusion}

Ehlers-Danlos disease appears as a very unusual pathological entity through multiplicity and variability of its clinical expressions, which are sometimes very spectacular with acute attacks of pain, dystonia, dysautonomic discomfort, fatigue, intestinal obstruction, bladder retention or incontinence, acute respiratory syndrome, contrasting with the poverty of imaging or biological tests. Serious complications are possible: ruptured arterial aneurysm, appendicular or vesicular peritonitis and pneumothorax. It's actually a holistic approach that prevails in this disease which, especially in children, can be expressed in a respiratory mode. It should be mentioned, because it is very common, in front of dyspnea and bronchial congestion before attributing it to asthma. The remarkable effectiveness of oxygen therapy on two of the major and rebellious symptoms of this disease: fatigue and migraines but also cognitive disorders, effort dyspnea, must be emphasized, so that pneumologists know how to prescribe it, even if oxygen dosage in the blood is normal and does not deprive these people with multiple handicap situations of the treatment which proves to be the most effective in this pathology rebellious to therapeutics.

\section{References}

1- Tinkle B., Castori M., Berglund B., Cohen H., Grahame R, Kazkaz H., Levy H., Hypermobile Ehlers-Danlos (aka EhlersDanlos syndrome type III) and hypermobility syndrome and Ehlers-Danlos syndrome hypermobility type) : clinical description and natural history, Am J Med Genet C Semin Med Genet. 2017 Mar;175(1):48-69.

2- Malfait F, Francomano C, Byers P, Belmont J, Berglund B, Black J, Bloom L, Bowen JM, Brady AF, Burrows NP, Castori M, Cohen H, Colombi M, Demirdas S, De Backer J, De Paepe A, Fournel-Gigleux S, Frank M, Ghali N, Giunta C, Grahame R, Hakim A, Jeunemaitre X, Johnson D, Juul-Kristensen B, Kapferer-Seebacher I, Kazkaz H, Kosho T, Lavallee ME, Levy H, Mendoza-Londono R, Pepin M, Pope FM, Reinstein E, Robert L, Rohrbach M, Sanders L, Sobey GJ, Van Damme T, Vandersteen A, Van Mourik C, Voermans N, Wheeldon N, Zschocke J, Tinkle B. The 2017 International Classification of the Ehlers-Danlos Syndromes. American Journal of Medical Genetics 2017;175C:8-26.

3- Hamonet C., Brock I., Pommeret St., Pommeret S., Baeza C., Metlaine A., Clinical somatosensory (ECSS-62) scale validation about 626 patients. Bull. Acad., Natle, Med., 2017, 201, nos 1-2-3, 405-415.

4- Tserchnogobow N. A., Über einen fall von cutis laxa, Dermatologic and Venerologic Society, Nov. 13 1891, Monatshefte für praktische dermatiology, Hamburg, 1892, 14:76.

5- Ehlers E. Cutis laxa. Neigung zu Haemorrhagien in der Haut, Lockering meherer Artikulationen, Dermatologische Zeitschrift. Danish society of dermatology and Venerology, Copenhagen, december 15 1900. Derm.Zschr. 8:173, 1901.

6- Hamonet C1, Brissot R., Anne Gompel A., Baeza-Velasco C., Guinchat V., Brock I, Ducret L, Pommeret S. and Metlaine A. Ehlers-Danlos Syndrome (EDS) - Contribution to Clinical Diagnosis - A Prospective Study of 853 Patients, EC Neurology 10.6 (2018).

7- C. Hamonet, M. Vienne, C. Leroux, MP Letinaud, J. Paumier, B. Debecq, A. Matlaine, I. Brock, F. M. Bird, Respiratory manifestations in Ehlers-Danlos syndrome (EDS). New treatments options. Journal de réadaptation médicale 2016:36. 56-61.

8- Hamonet Claude, PhD, Manicourt, Pommeret S., EhlersDanlos Clinical diagnosis. Symposium on the Ehlers-Danlos Syndromes (Ehlers-Danlos society New York). Ghent (Belgium). September 26-29, 2018.

9- Trinh Hermanns-Lê, Gérald E Piérard. Skin Ultrastructural Clues on the Impact of Ehlers-Danlos Syndrome in Women. J. of Dermatological Res. 2016 September; 1(3): 34-40 ISSN 2413-8223.

10- R. Grahame, Preface, Ehlers-Danlos, the disease forgotten by medicine, l'Harmattan, Paris, 2018/2019.

11- Roy Meadow, Munchausen syndrome by proxy. The hinterland of child abuse, The Lancet, vol.310, no8033,1977, p.343-345.

12- C. Hamonet, A. Gompel, G. Mazaltarine, I. Brock, C. BaezaVelasco , J.D Zeitoun and B. Bienvenu. Ehlers-Danlos Syndrome or Disease? J Syndromes July 2015 Vol.:2, Issue:1

13- Miget A., le syndrome d'Ehlers-Danlos, thèse Médecine Paris, 1933, Louis Arnette.

14- Alan Hakim, Rodney Grahame, A simple questionnaire to detect hypermobility: An adjunct to the assessment of patients with diffuse musculoskeletal pain International Journal of Clinical Practice, May 2003, 57(3):163-166

15- Claude Hamonet, Daniel Manicourt, Trinh Hermanns-Lê Pommeret Stanislas, Antonio Bulbena, Rodney Grahame, Jaime Bravo, Pradeep Chopra, Michael Holick, Carolina Baeza-Velasco, Vincent Guinchat Cora Cravero, Cristina Carravilla, Magdalena Perez. Ehlers-Danlos, Nuevos apportes de la investigacion medica una certeza para el diagnóstico y efficacia los tratamientos. IX Congresso internacional de medicamentos Huerfanos y enfermedades raras «Las enfermedades raras un desafi o para los global» SEVILLA 13, 14 y 15 febrero de 2019

16- R. Grahame, conclusions of first french colloquium "Treatments of Ehlers-Danlos syndrome". Journal de réadaptation médicale;2016.36:91

17- Antonio Bulbena, Carolina Baeza-Velasco, Andrea BulbenaCabre, Guillem Pailhez, Hugo Critchley, Pradeep Chopra, Nuria Mallorquei-Bague, Charissa Frank, Stephen Porges. Psychiatric and Psychological Aspects in the Ehlers-Danlos Syndromes,American Journal of Medical Genetics Part- C (Seminars in Medical Genetics) 175C:237-245 (2017).

18- -Castori M., Brad Tinkle B., Levy H., Grahame R.,Graham R.,Malfait F., Hakim A., A framework for The classifcation of joint hypermobility and related conditions. Americanjournal of 
mefical geneticsPart C (seminar in medical genetics) 175 C:148-157 (2017).

19- Hamonet C., Vienne M., Ehlers-Danlos syndrome (or disease) and respiratory function. About 1700 patients.18eme congrès de Pneumologie de langue française, Marseille january 24 2014.

20- Filippo Camerota, Manuela Galli, Veronica Cimolin, Claudia Celetti, Andrea Anciliano, David Blow, and Giorgio Albertini. The effects of neuromuscular taping on gait walking strategy in a patient with joint hypermobility syndrome/Ehlers-Danlos syndrome hypermobility type. Ther adv Musculskelet Dis. 2015 Feb; 7(1): 3-10.2

21- Raux M., Flamma M.N., Similowski T., C., Control of breathing: Physiology and functionnal testing in intensive care. Resuscitation, vol. 146, issue 6, October 2007, pages 511-52.

22- Bravo JF. La dysautonomie dans le syndrome Ehlers-Danlos type III. 2016. J. réadapt. Méd.36:52-55

23- Hakim A, O'Callaghan C, De Wandele I, Stiles L, Pocinki A, Rowe P. 2017. Cardiovascular autonomic dysfunction in Ehlers-Danlos syndrome-Hypermobile type. Am J Med Genet Part C Semin Med Genet 175C:168-174.

24- Claude Hamonet, Lucie Chevallier, the scandal of false accusations of physical violence or Münchausen syndrome by proxy, made to parents of children with Ehlers-Danlos disease. Fith Ehlers-Danlos international Hamonet colloquium. EhlersDanlos in Human and animal. Alfort National veterinary school, Universitary Paris-Est-Créteil (UPEC) October 26 2019.

25- Claude Hamonet, Isabelle Brock, Marie Hamonet-Dewez, Regine Brissot, Local multiple injections as a very efficient treatment of intractable Pains in Ehlers-Danlos Disease. The Dysproptioception Hypothesis. EC Anaesthesia 5,9(2019), 290-296.

26- Dupuis EG, Leconte P, Vlamynck E., Sultan A., Chesneau C., Denise P., Bienvenu B., Decker LM, . Ehlers-Danlos Syndrome hypermobility type: impact of Somatosensory orthoses on postural Control (a pilot study), front hum Neuroci. 2017 jun. $8 ; 11: 283$.

27- Hamonet C and Ducret L, Ehlers-Danlos, Proprioception, Dystonia, Dysautonomy, L-Dopa and Oxgenotherapy's Efficacy, J Alzheimers Neurodegener Dis 2019, 5: 031

28- Hamonet C, Geoffroy N, David C, Ducret L. Tissue Fragility and Ehlers-Danlos Syndrome Global Aggravation by Osteopathic Manipulations. J Neur \& Br Disord 3(2)- 2019.
This work is licensed under Creative Commons Attribution 4.0 License
Ready to submit your research? Choose Auctores and benefit from:

* fast, convenient online submission

* rigorous peer review by experienced research in your field

* rapid publication on acceptance

* authors retain copyrights

* unique DOI for all articles

* immediate, unrestricted online access

At Auctores, research is always in progress.

Learn more www.auctoresonline.org/journals/neuroscience-andneurological-surgery 